\title{
Investigation of phase-wise voltage regulator control logics for compensating voltage deviations in an experimental low voltage network
}

Hu, Junjie; Zecchino, Antonio; Marinelli, Mattia

Published in:

Electric Power Components and Systems

Link to article, DOI:

$10.1080 / 15325008.2016 .1218572$

Publication date:

2016

Document Version

Peer reviewed version

Link back to DTU Orbit

Citation (APA):

Hu, J., Zecchino, A., \& Marinelli, M. (2016). Investigation of phase-wise voltage regulator control logics for compensating voltage deviations in an experimental low voltage network. Electric Power Components and Systems, 44(19), 2133-2142. https://doi.org/10.1080/15325008.2016.1218572

\section{General rights}

Copyright and moral rights for the publications made accessible in the public portal are retained by the authors and/or other copyright owners and it is a condition of accessing publications that users recognise and abide by the legal requirements associated with these rights.

- Users may download and print one copy of any publication from the public portal for the purpose of private study or research.

- You may not further distribute the material or use it for any profit-making activity or commercial gain

- You may freely distribute the URL identifying the publication in the public portal 


\title{
Investigation of phase-wise voltage regulator control logics for compensating voltage deviations in an experimental low voltage
}

\author{
network \\ Junjie Hu, Antonio Zecchino, Mattia Marinelli* \\ Center for Electric Power and Energy, Technical University of Denmark, \\ DTU Risø Campus, Frederiksborgvej 399, 4000 Roskilde, Denmark.
}

\begin{abstract}
This paper investigates the control logics of an on-load tap-changer (OLTC) transformer by means of an experimental system validation. The experimental low-voltage unbalanced system consists of a decoupled single-phase OLTC transformer, a 75-metre $16 \mathrm{~mm}^{2}$ cable, a controllable single-phase resistive load and an electric vehicle, which has the vehicle-to-grid function. Three control logics of the OLTC transformer are described in the study. The three control logics are classified based on their control objectives and control inputs, which include network currents and voltages, and can be measured either locally or remotely. To evaluate and compare the control performances of the three control logics, all the tests use the same loading profiles. The experimental results indicate that the modified line compensation control can regulate voltage in a safe band in the case of various load and generation conditions.
\end{abstract}

Keywords: On-load tap-changer, Power transformer, Voltage control, Unbalanced system.

*Corresponding author: Tel:0045 20124369, Email address: matm@elektro.dtu.dk 


\section{Abbreviations}

DG: Distributed generation

DSO: Distribution system operator

MV/LV transformer: Medium-voltage/low-voltage transformer

OLTC: on-load tap changer

PV: Photovoltaic

VUF: Voltage unbalances factor

Phase-wise OLTC: decoupled single-phase OLTC with the possibility of tapping each phase independently.

3-phase OLTC: The controller changes the taps in three phases simultaneously.

\section{Introduction}

With the increasing penetration of distributed and renewable energy resources connected to the distribution network, network operators are facing voltage-deviation problems, such as voltage rise introduced by non-programmable photovoltaic generation [1]-[3], or voltage drop, owing to the increasing number of electric vehicles and heat pumps [4],[5]. To address the voltage problems, instead of choosing expensive expansion investments, even though the capacities of the grid are far from exhausted, network operators can consider the following options suggested in [6]: 1) voltage control using reactive power generation from PV inverters [7], [8]; 2) voltage control at the LV side of the MV/LV transformer by on-load tap changers (OLTC) [9], [10]; 3) active power derating of the PV production in case of overvoltage conditions [11]; and 4) battery storage/energy buffer at PV generator and MV distribution level [12]. Each solution is currently investigated by different stakeholders and their feasibility is overviewed in [6]. In addition, coordinated voltage control strategies, such as using the OLTC at the substation level and using the active/reactive power at the distributed generation level, are studied in the literature [13],[14]. 
In practice, several national standard bodies, such as CEI in Italy [15] and VDE in Germany [16] have updated the connection rules to enable the reactive power provision by the inverters' interfacing static generators, such as PV units, even at low-voltage levels. Different reactive power control methods have been set, with most relying on local measures on the busbar voltage or the produced active power. These can be summarized as: fixed $\cos \varphi, \cos \varphi(P)$ characteristic, fixed $Q, Q(U)$ droop function; and remote set values method. Other countries such as Denmark are currently in the process of defining the grid code for integrating massive distributed PV units. For instance, PV plants with power output greater than $11 \mathrm{~kW}$ are subject to the recently released technical regulations provided by the Danish transmission system operator [17]. However, for power output of less than $11 \mathrm{~kW}$, no regulations are given. Thus, this study will focus on voltage control solutions not provided by inverters but by other smart devices, such as OLTC transformer.

In [9], a real-time control of a LV on-load tap-changer-fitted transformer is proposed to regulate the voltage at the LV feeders. The performance of the proposed control logic is investigated under two types of input: monitored data at the end of points, as well as estimated values. The results indicate that the control logic with remote monitoring successfully keeps the voltage of customers within the EN50160 standard. The study is extended in [18], where the same authors assess the performance of the proposed OLTC control logic, considering different remote-monitoring schemes and control cycles. The assessment showed that the adoption of monitoring only at the end of each feeder and a 30-minute control cycle can provide a satisfactory performance of customer voltages. In [19], the authors discussed the voltage control with on-load tap changers in medium-voltage feeders, in the presence of distributed generation. Concerning the OLTC, two kinds of controls are discussed for the conventional distribution grid: the first is based on the local voltage measurement, while the second is intended for remote voltage regulation through line-drop compensation (LDC). With the provided background, the authors studied the effect of both controls on a distribution network in the presence of 
DG. The analysis showed that OLTC and OLTC with LDC are robust against DG, whereas DG can negatively affect the voltage regulation provided by LDC. Therefore proper coordination between DG and LDC is needed to ensure voltage regulation, while enhancing the integration of DG. In [20], a coordinated method, based on placing a remote terminal unit (RTU) at each DG and each line capacitor, is proposed to regulate the voltage of multiple feeders in the presence of DGs effectively. These RTUs are used to generate estimated voltage profiles that provide the input to the OLTC. Simulation results showed the technique enabled a considerable increase in the allowed DG-injected power to the system.

All the research activities described in the above deal with the OLTC's applications on voltage control in three-phase balanced systems, using a synchronized tap-changer in the three phases. The studies [9], [18]-[20] do not take into account the voltage-unbalance effect in low-voltage networks as a result of the users' single-phase connections, which usually happens to PV inverters, typically in domestic installations, as well as single-phase EV charging features. This kind of connection for the PV and EV charging could worsen the power-flow unbalance already existing in these systems, owing to the unbalanced load connections. In addition, the current studies focus on simulation-based validation that means experimental-based validation is still largely missing in the literature. To address the aforementioned problems, several studies are performed to investigate the control performance provided by a single-phases on-load tap-changer transformer [21]-[25] and validate the OLTC control in an experimental environment [26],[27].

In [21], an OLTC circuit is developed for use with a low-voltage transformer $(10 / 0.4 \mathrm{kV}$, or equivalent), in which the tap position could be set independently for each low-voltage feeder. To model the low-voltage system and the control logic of OLTC, the author uses two simulation tools: Excel and Simulink. The controller takes the measurement from the far end of the feeder. If the farend voltage is below the minimum limit, the control block increases the tap setting by one step. If the 
far-end voltage is above the maximum limit, the control block decreases the tap setting by one step. The results showed that the voltage could be kept within limits. In [22], phase-wise OLTC is assessed technically in Flemish LV distribution grids. Compared to [21], the proposed tapping logic considers the influence of PV in terms of active power injection. The simulation is performed in DigSilent PowerFactory, and the results showed that the phase-wise OLTC partly eliminates the violations of both voltage limits and thermal constraints. However, voltage unbalances can increase owing to the independent tap-changing control per phase. In [23]-[25], the same authors investigated the capability of phase-wise OLTC, with the objective of evaluating the hosting capacity of a distribution network characterized by high PV penetration. In the studies, details regarding the modelling and control algorithms of the OLTC are presented. The simulations are performed in Digsilent PowerFactory. The results showed that the phase-wise OLTC can significantly improve the penetration of PVs, since it reduces phase-neutral voltage deviations from the rated value, with acceptable increases of the voltage unbalance factor. Regarding field trials, [26] and [27] describe how a 3-phase OLTC, together with reactive power provision from DG, was tested in two substations. In the field trials, measuring information was collected from the selected critical nodes. The measurement was used as the input for the central controller to regulate the voltage. The trials indicated that: 1) detailed simulation is essential for developing the real time control algorithms; 2) The communication delay and the delay of averaging the signal have to be taken into account, to manage the stability of the control loop in terms of reactive power oscillations; 3) The noise level of the measuring data needs to be treated to filter out disturbances and erroneous converter readings; and 4) The given limits of the voltage band are not violated at times of high DG.

In this study, we aim to examine the control logics of a phase-wise on-load tap-changer transformer in an experimental low-voltage network, considering the line-drop compensation technology. To achieve the objective, the experimental low-voltage system is built and three types of control logic 
with regard to the OLTC are studied in the system. The highlights of this study include the following: 1) The phase-wise on-load tap-changer transformer is tested experimentally in the study, which is reported for the first time in the literature addressing voltage rise/drop problems in an active distribution system; and 2) An active distribution system is realized experimentally and its voltage characteristics are set so that it can emulate the features of possible future power-distribution systems. The rest of the paper is organized as follows: In Section 2, the experimental system set-up is described. Section 3 presents four types of control logic of an OLTC transformer. In Section 4, two methods of calculating the voltage drop in an unbalanced distribution network are presented, which will be used for a modified LDC control logic. Experimental results are presented in Section 5, to illustrate the performance of the proposed control logic. Finally, discussion and conclusions are reported in Section 6.

\section{The experimental system set-up}

Fig. 1 shows a diagram of the experimental system, which consists of SYSLAB busbar (power supply), a decoupled single-phase OLTC transformer, a 75-metre-long $16 \mathrm{~mm}^{2}$ cable, a controllable single-phase load, and an electric vehicle, which is able to provide a vehicle-to-grid (V2G) service.

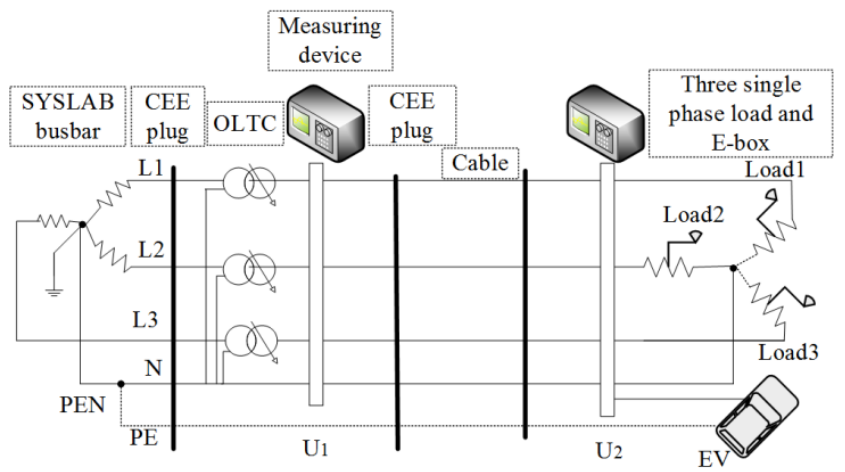

Fig. 1. Experimental system diagram layout

The electrical system is presented in Fig. 2 and the components are highlighted in yellow. 


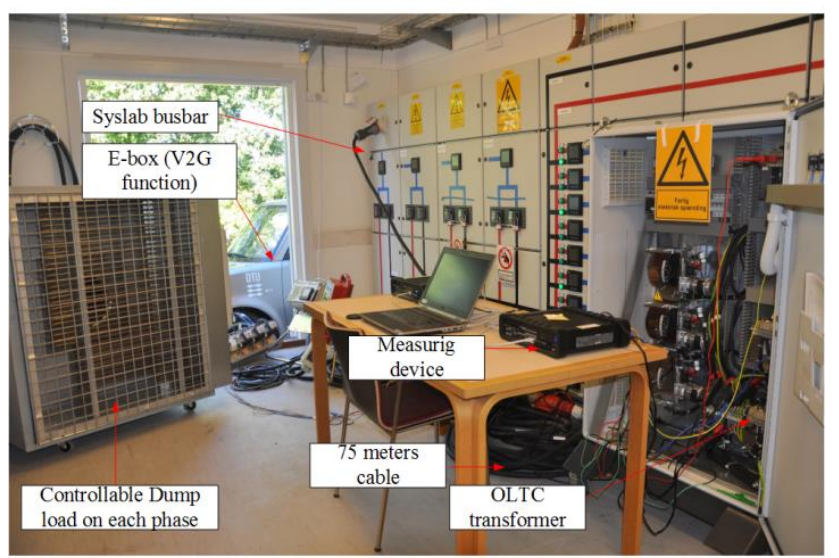

Fig. 2. Experimental system set-up

Each component is introduced briefly in the following paragraphs:

\subsection{Syslab busbar}

SYSLAB is a laboratory facility for the development and test of control and communication technology for active and distributed power systems. The facility is spread across four sites at the DTU (Technical University of Denmark) Risø campus. Its backbone is formed by a $400 \mathrm{~V}$ grid, with sixteen busbars in six substations. A central three-phase busbar crossbar substation allows the flexible selection of different grid topologies. Energy resources are distributed geographically with a system diameter of about $1 \mathrm{~km}$. The current system set-up is located at one site of SYSLAB, characterized by a short-circuit power of 0.6 MVA.

\subsection{OLTC transformer}

The phase-wise OLTC transformer used in the experimental system is an automatic voltage stabilizer (AVS) from Schuntermann $\mathrm{GmbH}$, with a rated power of $35 \mathrm{kVA}$. This device has the function of stabilizing the voltage individually on each phase. Automatic Voltage Stabilizers operate on a closed loop control. The output voltage is measured and compared with a highly stable reference voltage in an electronic control unit. Whenever the output voltage deviates from the reference by more than $1 \%$, 
the servomotor is switched on until the output voltage has again reached its nominal value. The rated current is $50 \mathrm{~A}$ and at $230 \mathrm{~V}$ that gives the AVS a rated power of $11.66 \mathrm{kVA}$ per phase. The reference voltage is set manually. The AVS allows a regulation of the output voltage of $\pm 10 \%$ of the rated voltage.

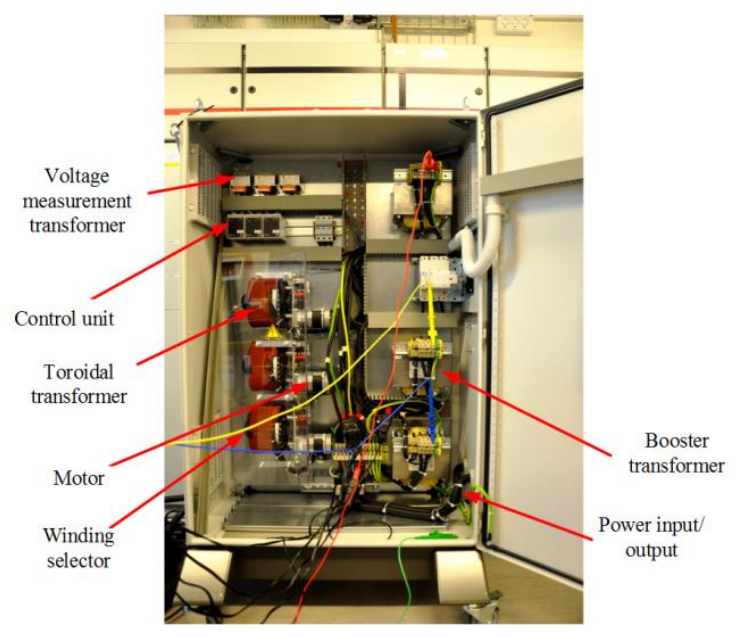

Fig. 3. Internal structure of the transformer

In Fig. 3 its internal structure is shown: three single-phase toroidal coil transformers are equipped with winding selectors connected to three servo motors, controlled according to voltage measurements at the secondary side, coming from three single-phase voltage measurement transformers. Three single-phase booster transformers can be seen on the right-hand side. Their main function is to split the total power among two steps of transformation, reducing the size of the three motors.

The tap operation has been analysed by monitoring the RMS values of phase-neutral voltages at the secondary side, while tap activities take place. The operation is described by the voltage trend reported in Fig. 4. 


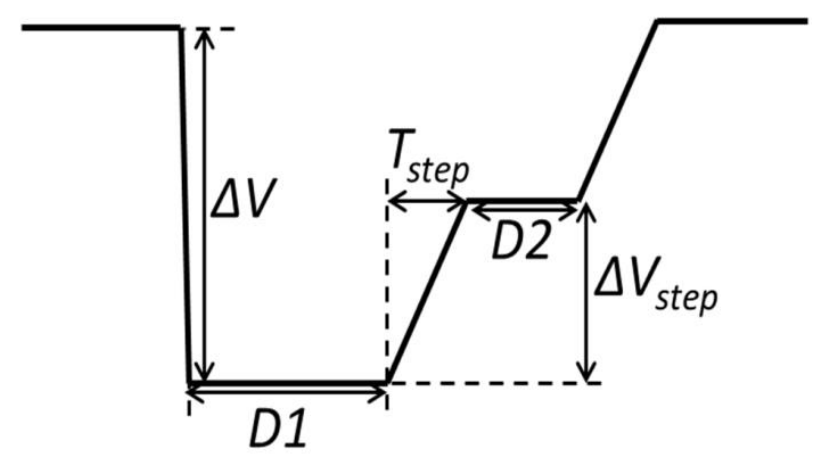

Fig. 4. Dynamics of the voltage owing to tap action

Specifically, it can be noticed that, after the voltage drop $\Delta V$, a delay-time $D 1$ preventing tap actions as a result of short-term voltage variations precedes the voltage increase $\Delta V_{\text {step }}$ caused by the tap action, whose duration has been named $T_{\text {step }}$. Between two consecutive steps, a certain time delay $D 2$ has been detected. Test results have shown that the average value of $\Delta V_{\text {step }}$ is $1.44 \mathrm{~V}$ (per tap action). Consequently, a total number of 32 steps ( \pm 16 from the '0-position') was obtained, achieving, in this way, the expected regulation range $\pm 10 \%$ of the rated voltage. Regarding $D 1$ and $T_{\text {step }}$, values of $60 \mathrm{~ms}$ were found for both parameters, while D2 amounted to $40 \mathrm{~ms}$. It is important to underline that the sampling time of the measurement device is $20 \mathrm{~ms}$.

\subsection{Controllable resistive dump load}

A $45 \mathrm{~kW}$ load unit (i.e., $15 \mathrm{~kW}$ per phase, adjustable with steps of $0.1 \mathrm{~kW}$ ) equipped with a threephase CEE 63 A plug was utilized. The load consists of a set of resistors of different size, which can be combined in order to achieve the desired power consumption. The operation is done independently on each phase. It is therefore clear that the load is representable with a constant-impedance model, according to the ZIP theory [28]. Note that the unit is manufactured so that the set active power value $P_{0}$ equals the effectively absorbed power $P_{\text {eff }}$ just under nominal voltage conditions $V_{0}$ (i.e., $230 \mathrm{~V}$ ). Otherwise the effective load power would change according to (1), based on the effective supply 
voltage $V_{\text {eff }}$.

$$
P_{\text {eff }}=P_{0} *\left(V_{\text {eff }} / V_{0}\right)^{2}
$$

\subsection{Electric vehicle}

The utilized EV is an eBox; a conversion of a Toyota Scion $\mathrm{xB}$ vehicle into an electric-battery vehicle produced by AC Propulsion, USA [29]. The eBox is equipped with a $35 \mathrm{kWh}$ battery and a power electronics unit (PEU), capable of single-phase bidirectional power transfer up to $20 \mathrm{~kW}$. It is controlled by the EV computer that interfaces with the PEU, using a built-in vehicle smart link (VSL), or a direct vehicle management system (VMS). The VMS is utilized in this study and it allows the manual adjustment of the injected/absorbed current, limited to $16 \mathrm{~A}$. The $16 \mathrm{~A}$ is set because of the technical limitation of the single-/three-phase switchboard used in the experimental voltage network to which the EV is connected. With reference to [28], the EV is represented by a 'constant-current' model. Thus, the behaviour is characterized by a constant ratio of active power and voltage. Thus the injected power $P_{e f f}$ would deviate from the one under nominal condition $P_{0}$ according to (2). $V_{e f f}$ and $V_{0}$ have the same meanings as the one in (1).

$$
P_{\text {eff }}=P_{0} *\left(V_{\text {eff }} / V_{0}\right)
$$

\subsection{Measurement device and Cables}

The measurement devices used in this study have the capability to measure individual phase voltage and currents, as well as the ones from the neutral phase. Therefore, the devices allow us to analyse the voltage and current profiles on each phase of the system, and evaluate the control performance of the on-load tap-changer transformer. The LV cable is a three core plus neutral $16 \mathrm{~mm} 2,75 \mathrm{~m}$ long. The kilometric impendence is $1.5+\mathrm{j} 0.09 \mathrm{Ohm} / \mathrm{km}$. 


\section{Operational Principles of on-load tap-changer transformer and line-drop compensation}

technology

In this section, we introduce four kinds of control logics (CL) related to phase-wise OLTC, namely:

- CL1, OLTC with local measurement.

- $\quad$ CL2, OLTC with remote measurement.

- CL3, line-drop compensation (LDC) control.

- CL4, modified LDC control.

The working principles of these four types of control logics are described as follows.

\subsection{CL1: OLTC control with local measurement:}

Fig. 5 illustrates the operational principle of CL1. The OLTC will keep the local voltage constant within the range of the reference voltage. The control unit reference voltage can be manually set on each phase. In an active distribution network, where distributed energy resources are connected, the voltages on the three phases can differentiate, meaning that the voltage at the remote busbar can violate the voltage band defined in the EN50160 standard, even though the voltage is regulated in a safe band at the secondary side of the OLTC transformer. 


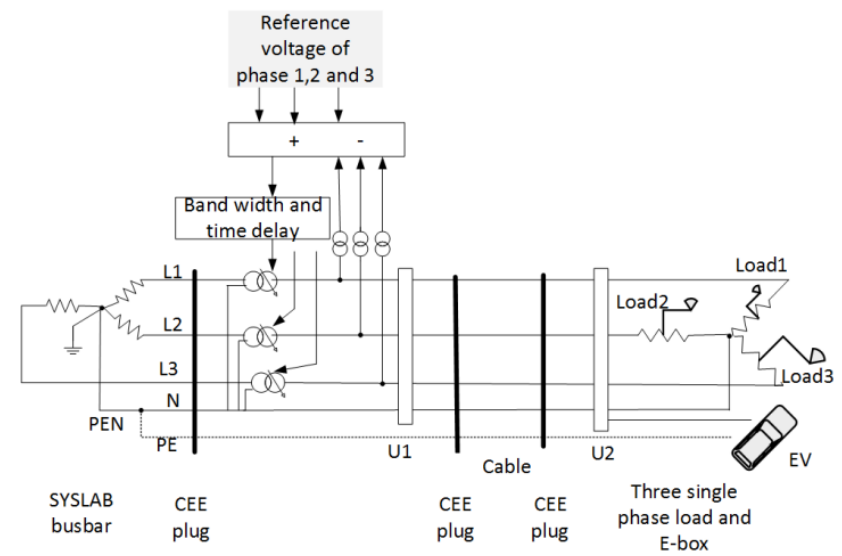

Fig. 5. Basic OLTC operational principle

\subsection{CL2: OLTC with remote measurement}

Fig. 6 shows the operational principle of the OLTC facilitated with remote measurement. It means that OLTC will keep the remote busbar voltage within the range. In contrast to CL1, the voltage profile at the secondary side of the OLTC transformer might be out of the voltage band when tapping, in order to regulate the voltage at the remote busbar.

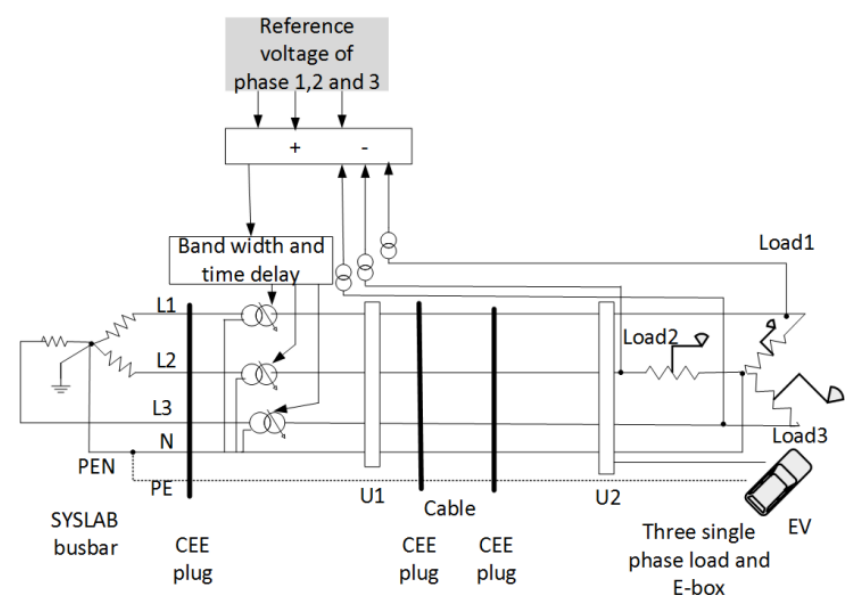

Fig. 6. Operational principle for an OLTC with remote measurement 


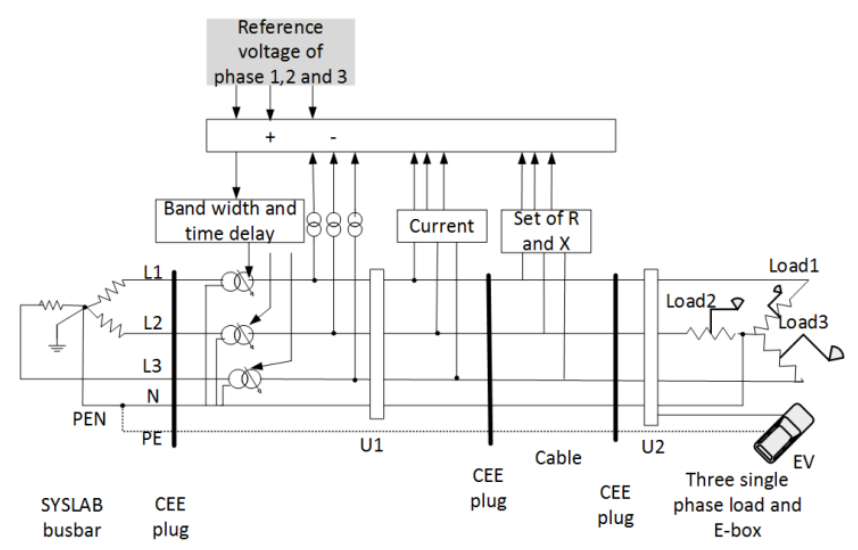

Fig. 7. Operational principle of LDC control

Compared to CL1 and CL2, the LDC control estimates the line-voltage drop based on the linecurrent measurement, resistance and reactance $(R$ and $X)$ and the local voltage measurement to get the voltage of the remote bus regulated within the range. The working principle is shown in Fig. 7. This is normally achieved by dial settings of the adjustable resistance and reactance elements of a unit, called the 'line-drop compensator', located on the control panel of the voltage regulator [30]. Determination of the appropriate dial settings depends upon whether or not any load or small renewable energy source unit is connected/disconnected to the feeder, between the voltage regulator and the regulation point. In terms of the details of selecting the proper $R$ and $X$, this is described in [19]. Note that in an unbalanced network, the settings of $R$ and $X$ need to consider the mutual interactions among the three phases. Therefore, in addition to the phase current measurements, the neutral current and impedance also need to be measured. 


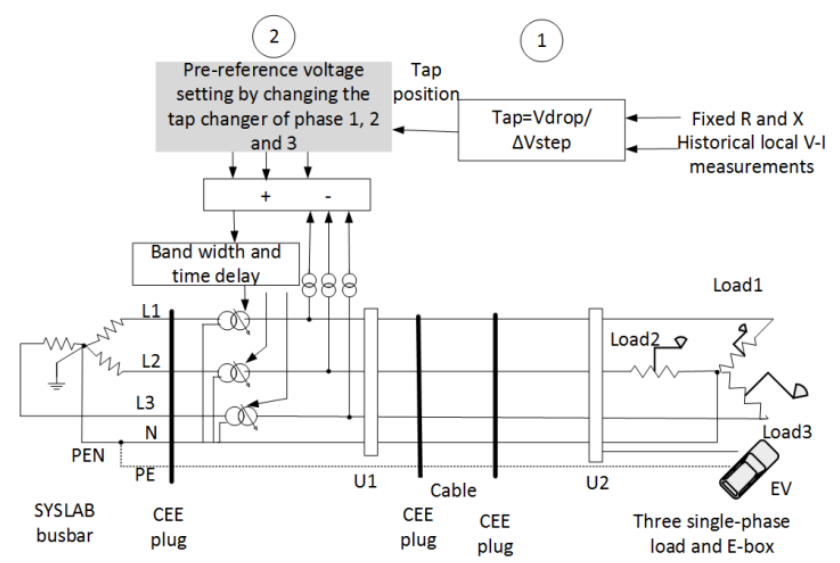

Fig. 8. Operational principle of modified LDC control

In this study, as the OLTC transformer does not have a control panel for setting $R$ and $X$ of the line, thus a modified LDC control logic is proposed. The proposed control logic uses the manual voltage reference setting feature available on the control unit and regulates the voltage at the remote bus by considering the voltage drop. Two steps, illustrated in Fig.8, are included in this proposed control logic:

1) The voltage drop is calculated by using historical measurements of the local voltage and current, and by knowing the cable impedance value. With the known voltage drop $V_{\text {drop }}$ and $\Delta V_{\text {step }}$, the preset tap position is calculated, where the $\Delta V_{\text {step }}$ has been defined in Section 2.2.

2) The calculated tap changer position is pre-set to compensate the predicted voltage drop. After these two preliminary steps, the OLTC is operated according to the control logic CL1.

\section{Modified LDC control logic in an unbalanced distribution network: voltage drop calculation}

In this section, we present a detailed method to calculate the voltage drop which is needed for the modified LDC control logic. The method considers the presence of the return wire. In an unbalanced power network, mutual interactions among the phases and between each phase and the neutral need to 
be taken into account for a correct grid analysis of the operation. Since the current on the neutral is no longer zero, a correspondent voltage drop along the neutral conductor appears which cannot be neglected, as it would be for balanced situations. Therefore, considering the feeder as a single threephase system composed of three phases and the neutral, the scheme reported in Fig. 9 needs to be considered.

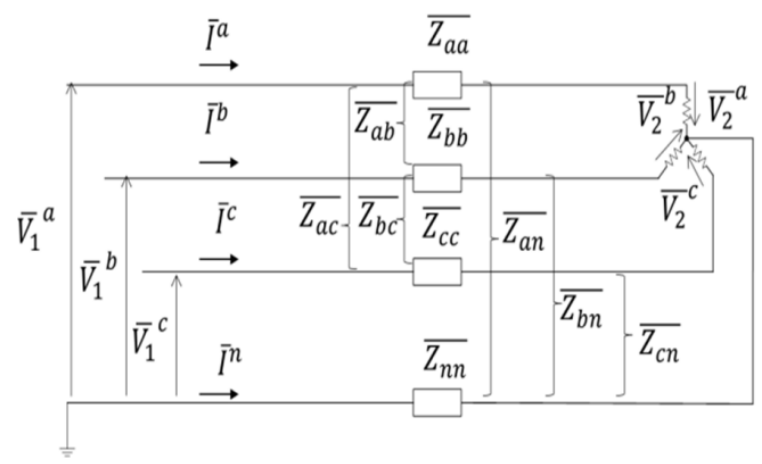

Fig. 9. Complex voltage drop estimation method

The single-phase voltage drop along the cable for phase $a$ is calculated as in (3), by applying Kirchhoff's voltage law around the circuit, differently at each phase.

$$
\overline{\Delta V}^{a}={\overline{V_{1}}}^{a}-{\overline{V_{2}}}^{a}=\left(\overline{Z_{a a}}-\overline{Z_{a n}}\right) \cdot \bar{I}^{a}+\left(\overline{Z_{a b}}-\overline{Z_{a n}}\right) \cdot\left(\bar{I}^{b}+\bar{I}^{c}\right)+\left(\overline{Z_{a n}}-\overline{Z_{n n}}\right) \cdot \bar{I}^{n},
$$

In our work, since the system is a LV system, $\overline{Z_{a b}}$ and $\overline{Z_{a n}}$ can be neglected, so that equation (3) can be simplified as in equation (4).

$$
\overline{\Delta V}^{a}=\left(\overline{Z_{a a}}\right) \cdot \bar{I}^{a}+\left(-\overline{Z_{n n}}\right) \cdot \bar{I}^{n},
$$

Similarly, the voltage drops along the other two phases can be calculated.

\section{Experimental system and results}

\subsection{Testing case description}

To evaluate and compare the three control logics (CL1, CL2 and CL4) of the OLTC transformer in the experimental system, phase-wise power profiles of the load and EV are described in Table 1. The 
setting of the power profiles considers the features of an unbalanced distribution network. The load on phase $a$ has been changed to the power from the EV in Load/EV conditions 6 and 7, and the resistive single-phase loads of phases $\mathrm{b}$ and $\mathrm{c}$ have been maintained. As for any considered conditions, the three phases are affected by different power flows, in terms of both direction and loading, thus the main objective of this test is the analysis of the operations of the phase-wise OLTC in the presence of different unbalanced situations and power-flow directions. As the EV allows the manual adjustment of the current, the increase in the injected power at phase $a$ has been set manually to $8 \mathrm{~A}$ and $16 \mathrm{~A}$.

Table 1 Phase-wise power profiles of load and EV to compare three control logics

\begin{tabular}{|l|c|c|c|}
\hline Load/EV condition & Phase a & Phase b & Phase c \\
\hline 1 & $0 \mathrm{~kW}$ & $0 \mathrm{~kW}$ & $0 \mathrm{~kW}$ \\
\hline 2 & $3.4 \mathrm{~kW}$ & $0 \mathrm{~kW}$ & $3.4 \mathrm{~kW}$ \\
\hline 3 & $6.7 \mathrm{~kW}$ & $0 \mathrm{~kW}$ & $6.7 \mathrm{~kW}$ \\
\hline 4 & $6.7 \mathrm{~kW}$ & $6.7 \mathrm{~kW}$ & $6.7 \mathrm{~kW}$ \\
\hline 5 & $3.4 \mathrm{~kW}$ & $6.7 \mathrm{~kW}$ & $3.4 \mathrm{~kW}$ \\
\hline 6 & $-1.8 \mathrm{~kW}(=-8 \mathrm{~A} @ 230 \mathrm{~V})$ & $6.7 \mathrm{~kW}$ & $3.4 \mathrm{~kW}$ \\
\hline 7 & $-3.7 \mathrm{~kW}(=-16 \mathrm{~A} @ 230 \mathrm{~V})$ & $6.7 \mathrm{~kW}$ & $3.4 \mathrm{~kW}$ \\
\hline
\end{tabular}

\subsection{Results of Control logics comparison}

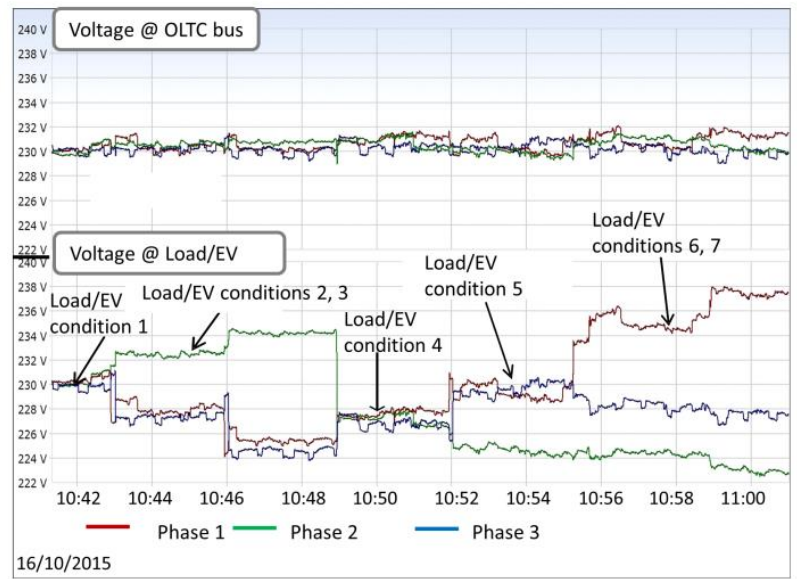

Fig. 10. Voltage measurement at OLTC bus and load/EV bus in the case of CL1 
Fig. 10 shows the phase-neutral voltages at the two measurement points, in the scenario characterized by conventional OLTC operations CL1; i.e. considering local phase-neutral voltage measurements. It is noticed that, thanks to the tap-changing activities, the voltages at the OLTC or local bus (the controlled bus), are kept within the safe band. On the other hand, at the load/EV or remote bus they deviate unevenly from the rated value of $230 \mathrm{~V}$, according to the grade of unbalance. Specifically, it can be noticed that the larger the difference of the three single-phase loads (see Table 1), the higher the deviations. It is also noticeable that the deviations decrease on the three phases, in correspondence to the balanced condition characterized by active power absorption of $6.7 \mathrm{~kW}$ on all phases (condition 4). Moreover, with regard to the most extreme conditions (6 and 7) - i.e., when the EV only injects current on one phase, while the other two absorb unevenly — the deviations are even more accentuated than for conditions 2 and 3 , when the unbalance is obtained through different grades of loading on the three phases.

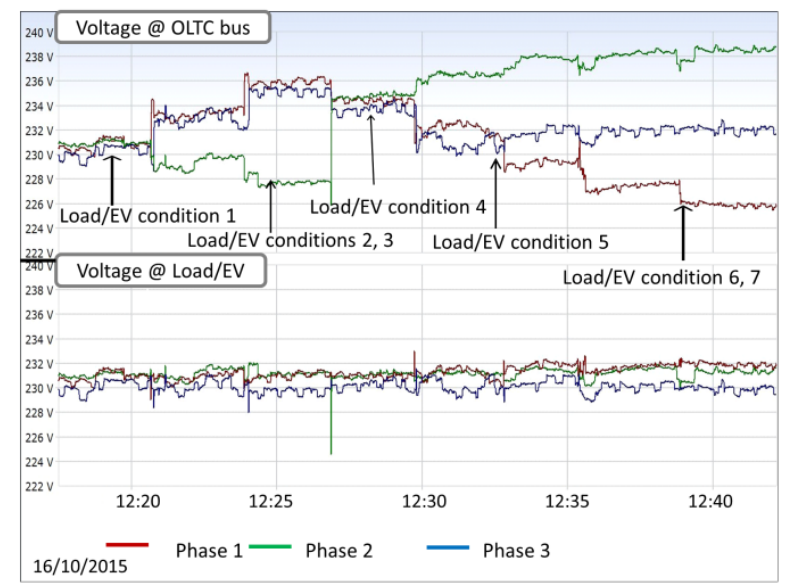

Fig. 11. Voltage measurement at OLTC bus and load/EV bus in case of CL2

Fig. 11 shows the phase-neutral voltages at the two measurement points, in the scenario characterized by OLTC operations based on phase-neutral measurements performed at the load/EV bus. It is noticed that the voltages at the load/EV bus (the controlled bus) are kept within the dead 
band, while on the other hand, at the OLTC bus, they deviate unevenly from the rated value of $230 \mathrm{~V}$, according to the grade of unbalance. Basically, the situation is the reverse of the previous one, since the considered load/EV conditions are the same. The only difference is the measurement point, which is also the control objective, has been shifted from the local to the remote bus. Again, note that the larger the difference of the three single-phase loads, the higher the voltage deviations. It is also noticeable that the deviations are even on the three phases, in correspondence with the balanced condition characterized by the active power absorption of $6.7 \mathrm{~kW}$ on all phases (condition 4 ).

As explained in Section 3.4, three stages are contained in the modified LDC control; i.e., CL4. To operate CL4 in real time, a pre-reference voltage setting of the tap changer is needed. Considering the various load/EV conditions defined in Table 1, Table 2 defines the position of the tap changer for each phase $\left(n^{a}, n^{b}, n^{c}\right)$, which will be set before every change of the load/EV condition, with the purpose of counteracting the voltage change on each phase. The tap value is calculated based on (5) in which the value of $\Delta V^{x}$ is taken from the experimental result of CL1, while $\Delta V_{\text {step }}$ is $1.44 \mathrm{~V}$ as explained in Section 2.2. The calculation of (5) is performed using Microsoft Excel Spreadsheet in a different computer.

$$
n^{x}=\frac{\Delta V^{x}}{\Delta V_{\text {step }}}, x \in\{a, b, c\}
$$

A negative value in the table means an increase in the voltage at the secondary side of the OLTC, while a positive value means a decrease in the voltage.

Table 2 Definitive tap table used for CL4 in real-time operation

\begin{tabular}{|l|c|c|c|}
\hline Load/EV condition & $n^{a}$ & $n^{b}$ & $n^{c}$ \\
\hline 1 & 0 & 0 & 0 \\
\hline 2 & -2 & 1 & -1 \\
\hline 3 & -4 & 2 & -2 \\
\hline 4 & -2 & -2 & -2 \\
\hline 5 & 0 & -3 & -2 \\
\hline 6 & 3 & -4 & -3 \\
\hline 7 & 4 & -5 & -3 \\
\hline
\end{tabular}


With this table, at each step of the operation before changing the load/EV conditions, we change the tap changer preventively. The corresponding voltage profiles at the secondary side of the OLTC bus and the Load/EV bus are presented in Fig. 12.

Comparing Fig. 12 and Fig. 11, it is observed that CL4 keeps the voltage at the Load/EV bus in a similar band as the one presented in CL2. However, with this method the control of the voltage is not as precise as it was for the case presented by CL2. This may due to 1 (or 2) more tap positions on phase $c$, in the case of load/EV conditions 5,6 and 7. Nevertheless, it presents and validates an approach for this type of on-load tap-changer transformer.

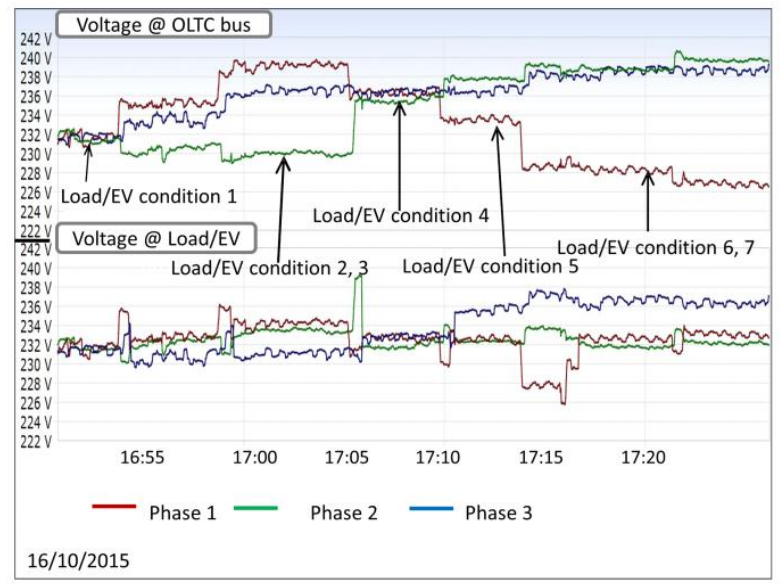

Fig. 12. Voltage measurement at OLTC bus and load/EV bus in case of CL4

As deduced from Table 3, in the case of CL1 and CL2, the deviations of the phase-neutral voltages to the correspondent reference value are kept within the voltage band at the controlled bus; i.e., at the local bus and remote bus, respectively. On the other hand, the uncontrolled bus is in both cases characterized by deviations up to $7.5 \mathrm{~V}$ in the case of Load/EV condition 7 .

Regarding the CL4 scenario, as also shown in Fig. 14, the preventive tap position adjustment allows a reduction in the variation at the remote bus to maximum deviations of 2.6 and $1.8 \mathrm{~V}$ for phases $a$ and $b$, respectively. On phase $c$ it can be noticed that the deviation in the case of load/EV 
conditions 6 and 7 is a bit higher: 4.6 and $4.9 \mathrm{~V}$, respectively. Although not perfectly matching the case CL2, the results indicate that this method is able to provide a good reduction of voltage variations at the remote bus, which in the case of traditional OLTC operations, based on local measurements (CL1), would have been drastically larger. Note that the switching operations inside the OLTC transformer are not precisely available, even though we can observe the position by looking into the toroidal transformer. Thus the validation of CL4 is only based on the voltage measurements.

Table 3 Summary of phase-wise voltage profiles under three control scenarios

\begin{tabular}{|c|c|c|c|c|c|c|c|c|c|c|}
\hline Scenario & $\begin{array}{l}\text { Load/EV } \\
\text { condition }\end{array}$ & $\begin{array}{l}\text { Desired } \\
\mathrm{V} a\end{array}$ & $\begin{array}{l}\mathrm{V}_{\text {meas }} a \\
\text { local }\end{array}$ & $\begin{array}{l}\mathrm{V}_{\text {meas }} a \\
\text { remote }\end{array}$ & $\begin{array}{c}\text { Desired } \\
\mathrm{V} b\end{array}$ & $\begin{array}{l}\mathrm{V}_{\text {meas }} b \\
\text { local }\end{array}$ & $\begin{array}{l}\mathrm{V}_{\text {meas }} b \\
\text { remote }\end{array}$ & $\begin{array}{c}\text { Desired } \\
\mathrm{V} c\end{array}$ & $\begin{array}{l}\mathrm{V}_{\text {meas }} c \\
\text { local }\end{array}$ & $\begin{array}{l}\mathrm{V}_{\text {meas }} c \\
\text { remote }\end{array}$ \\
\hline \multirow{7}{*}{ CL1 } & 1 & \multirow{7}{*}{$\begin{array}{c}230.6 \\
\text { @ } 1 \text { local } \\
\text { bus }\end{array}$} & 230.2 & 230.3 & \multirow{7}{*}{$\begin{array}{c}230.5 \\
\text { @local } \\
\text { bus }\end{array}$} & 230.0 & 230.3 & \multirow{7}{*}{$\begin{array}{c}230.1 \\
@ \text { local } \\
\text { bus }\end{array}$} & 230.0 & 229.8 \\
\hline & 2 & & 230.4 & 228.0 & & 230.6 & 232.5 & & 230.2 & 227.3 \\
\hline & 3 & & 230.2 & 225.5 & & 230.8 & 234.2 & & 230.0 & 224.5 \\
\hline & 4 & & 231.1 & 227.7 & & 230.8 & 227.2 & & 230.4 & 226.9 \\
\hline & 5 & & 230.4 & 229.4 & & 229.9 & 224.6 & & 230.4 & 229.6 \\
\hline & 6 & & 230.8 & 235.0 & & 231.0 & 224.4 & & 230.2 & 228.2 \\
\hline & 7 & & 231.4 & 237.4 & & 230.1 & 223.0 & & 229.8 & 227.5 \\
\hline & & & & & & & & & & \\
\hline \multirow{7}{*}{ CL2 } & 1 & \multirow{7}{*}{$\begin{array}{c}231.2 \\
\text { @ remote } \\
\text { bus }\end{array}$} & 230.8 & 230.9 & \multirow{7}{*}{$\begin{array}{c}231.2 \\
\text { @remote } \\
\text { bus }\end{array}$} & 230.9 & 231.0 & \multirow{7}{*}{$\begin{array}{c}230.1 \\
\text { @remote } \\
\text { bus }\end{array}$} & 230.2 & 230.1 \\
\hline & 2 & & 233.2 & 230.8 & & 229.3 & 231.2 & & 233.0 & 230.2 \\
\hline & 3 & & 235.9 & 231.0 & & 227.7 & 231.2 & & 235.2 & 229.7 \\
\hline & 4 & & 234.4 & 231.0 & & 234.8 & 231.1 & & 233.7 & 230.3 \\
\hline & 5 & & 232.3 & 231.4 & & 236.5 & 231.2 & & 230.9 & 230.1 \\
\hline & 6 & & 227.4 & 231.7 & & 238.2 & 231.5 & & 231.9 & 230.1 \\
\hline & 7 & & 225.9 & 231.9 & & 238.5 & 231.3 & & 232.1 & 229.9 \\
\hline & & & & & & & & & & \\
\hline \multirow{7}{*}{ CL4 } & 1 & \multirow{7}{*}{$\begin{array}{c}231.6 \\
\text { @remote } \\
\text { bus }\end{array}$} & 231.6 & 231.7 & \multirow{7}{*}{$\begin{array}{c}231.6 \\
\text { @remote } \\
\text { bus }\end{array}$} & 231.6 & 231.8 & \multirow{7}{*}{$\begin{array}{c}231.7 \\
@ \text { remote } \\
\text { bus }\end{array}$} & 231.7 & 231.5 \\
\hline & 2 & & 235.2 & 232.7 & & 230.4 & 232.2 & & 233.4 & 230.6 \\
\hline & 3 & & 239.1 & 234.2 & & 230.0 & 233.4 & & 236.5 & 231.1 \\
\hline & 4 & & 236.2 & 232.7 & & 235.4 & 231.8 & & 236.4 & 232.8 \\
\hline & 5 & & 233.5 & 232.6 & & 237.7 & 232.4 & & 236.5 & 235.6 \\
\hline & 6 & & 228.2 & 232.6 & & 238.7 & 231.7 & & 238.6 & 236.6 \\
\hline & 7 & & 226.8 & 233.1 & & 239.7 & 232.1 & & 238.6 & 236.3 \\
\hline
\end{tabular}

\section{Discussion and conclusion}

This study presented experimental operations of the on-load tap-changer transformer, which has the capability to regulate the voltage per phase. Three control logics were tested and compared in this study. The experimental test validates the control performance of the on-load tap changers. The study suggests that, using remote measurement (i.e., end of the LV feeder), the on-load tap-changer 
transformer can keep the voltage at the remote bus in an ideal band. However, this requires the availability of the remote measurement to the OLTC which, however, may be an expensive upgrade. To resolve this problem, a tap algorithm is defined that can compensate the voltage drop, and keeps the voltage at the ending bus in a safe band. It is noted that the system used in the study is a simplified network that cannot characterize all the features of a real distribution network, even though it is able to catch the most important. Future study includes two aspects: 1) investigate the OLTC's application in an active distribution network characterized by several subfeeders, where higher penetration of different distributed generations is present; in such a case, the voltage rise/drop estimation may need some rethinking; and 2) combine the OLTC control with smart-metering technology, where the measurements from the smart meters can be used as inputs for the OLTC transformer.

\section{Acknowledgments}

The authors would like to thank the financial support of the Danish EUDP programme for the ‘Energy Saving by Voltage Management' project (under grant number 5996648995411).

\section{References}

[1] E. Caamaño-Martín, H. Laukamp, M. Jantsch, T. Erge, J. Thornycroft, H. De Moor, S. Cobben, D. Suna, and B. Gaiddon, "Interaction between photovoltaic distributed generation and electricity networks," Prog. Photovoltaics Res. Appl., vol. 16, no. 7, pp. 629-643, 2008.

[2] M. Braun, T. Stetz, R. Bründlinger, C. Mayr, K. Ogimoto, H. Hatta, H. Kobayashi, B. Kroposki, B. Mather, and M. Coddington, "Is the distribution grid ready to accept large-scale photovoltaic deployment? State of the art, progress, and future prospects," Prog. photovoltaics Res. Appl., vol. 20, no. 6, pp. 681-697, 2012.

[3] T. Stetz, M. Kraiczy, M. Braun, and S. Schmidt, "Technical and economical assessment of voltage control strategies in distribution grids," Prog. Photovoltaics Res. Appl., vol. 21, no. 6, pp. 1292-1307, 2013.

[4] K. Knezovic, M. Marinelli, R. J. Moller, P. B. Andersen, C. Traholt, and F. Sossan, "Analysis of voltage support by electric vehicles and photovoltaic in a real Danish low voltage network," in Power Engineering Conference (UPEC), 49th International Universities, Cluj-Napoca, Romania, 2014, pp. 1-6.

[5] J. Hu, S. You, M. Lind, and J. Østergaard, "Coordinated charging of electric vehicle for congestion prevention in the distribution grid," IEEE Trans. smart grids, vol. 5, no. 2, pp. 703$711,2014$.

[6] A. Constantin, R. D. Lazar, and S. B. Kjær, "Voltage control in low voltage networks by Photovoltaic Inverters PVNET.DK,” Nordborg, Denmark, 2012.

[7] R. Caldon, M. Coppo, and R. Turri, "Distributed voltage control strategy for LV networks with 
inverter-interfaced generators," Electr. Power Syst. Res., vol. 107, no. 0, pp. 85-92, Feb. 2014.

[8] B. Meersman, B. Renders, L. Degroote, T. Vandoorn, and L. Vandevelde, "Three-phase inverter-connected DG-units and voltage unbalance," Electr. Power Syst. Res., vol. 81, no. 4, pp. 899-906, Apr. 2011.

[9] A. T. Procopiou, C. Long, and L. F. Ochoa, "Voltage control in LV networks: An initial investigation," Innovative Smart Grid Technologies Conference Europe (ISGT-Europe), 2014 IEEE PES. pp. 1-6, 2014.

[10] C. R. Sarimuthu, V. K. Ramachandaramurthy, K. R. Agileswari, and H. Mokhlis, "A review on voltage control methods using on-load tap changer transformers for networks with renewable energy sources," Renew. Sustain. Energy Rev., vol. 62, pp. 1154-1161, Sep. 2016.

[11] A. Kechroud, P. F. Ribeiro, and W. L. Kling, "Distributed generation support for voltage regulation: An adaptive approach,” Electr. Power Syst. Res., vol. 107, pp. 213-220, Feb. 2014.

[12] N. Jayasekara, P. Wolfs, and M. A. S. Masoum, "An optimal management strategy for distributed storages in distribution networks with high penetrations of PV," Electr. Power Syst. Res., vol. 116, pp. 147-157, Nov. 2014.

[13] F. Bignucolo, R. Caldon, and V. Prandoni, "Radial MV networks voltage regulation with distribution management system coordinated controller," Electr. Power Syst. Res., vol. 78, no. 4, pp. 634-645, Apr. 2008.

[14] R. Shivarudraswamy and D. N. Gaonkar, "Coordinated Voltage Regulation of Distribution Network with Distributed Generators and Multiple Voltage-control Devices," Electr. Power Components Syst., vol. 40, no. 9, pp. 1072-1088, Jun. 2012.

[15] "Italian Technical Standard CEI 0-21,” Normal Italiana, Milano, Italy, 2012.

[16] “German Technical Standard VDE-AR-N 4105," FNN - Forum Netztechnik / Netzbetrieb im VDE, 2011.

[17] Energinet.dk, "Technical regulation 3.2.2 for PV power plants with a power output above 11 kW," pp. 1-96, 2015.

[18] A. T. Procopiou, C. Long, and L. F. Ochoa, "On the Effects of Monitoring and Control Settings on Voltage Control in PV-Rich LV Networks," in IEEE PES General Meeting, 2015.

[19] F. A. Viawan, A. Sannino, and J. Daalder, "Voltage control with on-load tap changers in medium voltage feeders in presence of distributed generation," Electr. Power Syst. Res., vol. 77, no. 10, pp. 1314-1322, Aug. 2007.

[20] M. E. Elkhatib, R. El-Shatshat, and M. M. a Salama, "Novel coordinated voltage control for smart distribution networks with DG," IEEE Trans. Smart Grid, vol. 2, no. 4, pp. 598-605, 2011.

[21] D. Johnston, “On-Line Independent Tap-Changing of Each Feeder Supplied by a Low Voltage Distribution Transformer," J. Power Energy Eng., vol. 2, no. April, pp. 388-394, 2014.

[22] N. Efkarpidis, C. Gonzalez, T. Wijnhoven, D. Van Dommelen, T. De Rybel, and J. Driesen, "Technical Assessment of On-Load Tap-Changers in Flemish LV Distribution Grids," 3rd Int. Work. Integr. Sol. Power into Power Syst., 2013.

[23] M. Coppo, R. Turri, M. Marinelli, and X. Han, "Voltage Management in Unbalanced Low Voltage Networks Using a Decoupled Phase-Tap-Changer Transformer," in Power Engineering Conference (UPEC), 2014 49th International Universities, Cluj-Napoca, Romania, 2014, pp. $1-6$.

[24] A. Zecchino, M. Marinelli, J. Hu, M. Coppo, and R. Turri, "Voltage Control for Unbalanced Low Voltage Grids Using a Decoupled-Phase On-Load Tap-Changer Transformer and Photovoltaic Inverters," Proceedings of UPEC 2015. IEEE, Stoke-On-Trent, 2015.

[25] J. Hu, M. Marinelli, M. Coppo, A. Zecchino, and H. W. Bindner, "Coordinated voltage control 
of a decoupled three-phase on load tap changer transformer and photovoltaic inverters for managing unbalanced networks," Electr. Power Syst. Res., vol. 99, 2015.

[26] M. Stifter, B. Bletterie, H. Brunner, D. Burnier, H. Sawsan, F. Andren, R. Schwalbe, A. Abart, R. Nenning, and F. Herb, "DG DemoNet validation: Voltage control from simulation to field test," in Innovative Smart Grid Technologies (ISGT Europe), 2011 2nd IEEE PES International Conference and Exhibition on, Manchester, 2011, pp. 1-8.

[27] M. Stifter, R. Schwalbe, W. Tremmel, S. Henein, H. Brunner, B. Bletterie, A. Abart, F. Herb, and R. Pointner, "DG DemoNet: Experiences from volt/var control field trials and control algorithm advancements," in 2012 3rd IEEE PES Innovative Smart Grid Technologies Europe (ISGT Europe), 2012, pp. 1-7.

[28] "IEEE Task Force on Load Representation for Dynamic Performance, Load representation for dynamic performance analysis," IEEE Trans. Power Syst., vol. 8, no. 2, pp. 472-482, 1993.

[29] S. Martinenas, M. Marinelli, P. B. Andersen, and C. Træholt, "Implementation and demonstration of grid frequency support by V2G enabled electric vehicle," Proc. 49th Int. Univ. Power Eng. Conf. IEEE, Cluj-Napoca Rom., pp. 1-6, 2014.

[30] T. Gonen, "Electric power distribution engineering." CRC Press, 2014. 